\title{
Indonesia's 1st livestock vessel: deep insight of it is facility
}

\author{
Shabrina D. Wibawanti*1), Rudi Afnan ${ }^{1)}$ and Rudy Priyanto ${ }^{1)}$ \\ ${ }^{1)}$ Department of Animal Products Technology, Faculty of Animal Science, IPB University, \\ Bogor, West Java, Indonesia 16680
}

Submitted: 12 October 2019, Accepted: 03 March 2021

\begin{abstract}
Indonesia is an island country consisting of thousands of islands. The population of Indo-nesian people is increasing annually, making the need for food also increases, especially food originated from the livestock sector, namely beef. The difference in consumer centers' location with cattle production centers causes the need for transportation that can transport cattle from one island to another. Camara Nusantara is the first livestock vessel in Indonesia that started in 2015. Camara Nusantara took the ship's design from Australi-an livestock vessels, but there have not been any studies on the facilities and design of the Camara Nusantara ship. This research took place in Camara Nusantara ship for 5 days from Kupang, East Nusa Tenggara to Tanjung Priuk, Jakarta. The observation was done by noting and observing all facilities used from the livestock loading process in the port of Tenau to Tanjung Priok port. The results showed that there were still many shortcomings in the facilities used, so the need for improvement is done to avoid any stress generated during the transportation process that can cause further loss.
\end{abstract}

Keywords: Livestock vessel; Logistic; Sea transportation; Facility

*Corresponding Author: shabrinashaby@ymail.com 


\section{INTRODUCTION}

Indonesia consists of thousand islands, which is the population increasing every year. According to BPS (2018), Indonesia population reached 265 million people. A high number of the population, making Indonesia has a high number of food needs.

Beef is one of the primadonna products in the livestock sector. Unfortunately, central consumers and central cattle production in Indonesia is located on a different island. Most Indonesians are located in Java and Sumatra Island, while cattle production centers are located in East Indonesia, such as East and West of Nusa Tenggara. The difference in island location needs some transportation that can transport cattle from one island to another island. Before 2015, most of the transportation used goods to ship to transported cattle. Based on the function, design, and facility, it was not suitable to transported cattle. It was causing a high number of losing weight and a high number of loss for stakeholders.

The Government then established Indonesia's first livestock voyage in 2015, named Camara Nusantara. Until 2019, there are already six voyages of Camara Nusantara. KM Camara Nusantara I is a livestock vessel used to transport cattle from East Nusa Tenggara to Java Island. This vessel was used as one of the Government's solutions to send livestock from eastern Indonesia to Java Island. KM Camara Nusantara I is a livestock vessel that is part of the Government's sea toll program to improve livestock logistics distribution. Haryana and Nuryati (2016), livestock transportation mechanisms live by using the KM livestock ship Camara Nusantara more effectively than conventional transportation systems.

The cost, delivery time, and weight loss of livestock in the destination and the amount of cost and number of chains more efficient. The supply of live livestock from NTT and NTB by using animal vessels can shorten the supply chain. However, it cannot effectively lower the prices of fresh meats for the end consumer, especially in traditional markets. Comparing the transport mechanism between cattle ships and conventional transportation shows that transportation with KM Camara Nusantara shortens the travel time from one and a half months to one week. The cost reduction from RP 1.5 million-to Rp 1.1 millionlowered the weight loss of livestock (22\% to $5 \%$ ) and cut the supply chain from 13 points to 4 points (Haryana and Nuryati 2016).

Camara Nusantara was built based on Australia's livestock vessel. There has been no research about facilities in Camara Nusantara, whether its facilities already suitable for Indonesian livestock. In this research, the researcher observed Camara Nusantara facilities.

\section{MATERIALS AND METHODS Time and place}

This study was held in December 2018 and took place at KM Camara Nusantara, which carried cattle from Kupang to Tanjung Priok with 5 days of the journey.

\section{Working procedure}

Camara Nusantara ships consist of 4 decks (decks A, B, C, and double-decker). Both deck A and double-decker are below sea level, so they have limited fresh air and low airflow, while on deck $\mathrm{B}$ and deck $\mathrm{C}$ are above sea level, and there is fresh airflow. The feed given is dried grass for cattle on deck $A$ and stem and corn leaves for cattle on deck B and deck C. Total Travel KupangJakarta requires five days journey.

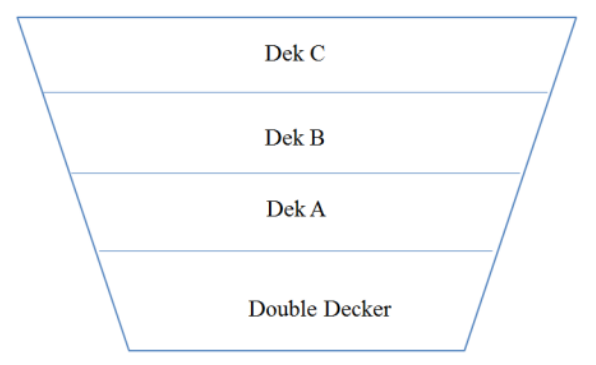

Figure 1. Picture Camara Nusantara deck 


\section{Tool}

The tools used in this research are Data Logger, livestock scales, camera, measuring tape, assessment form, and stationery for recording.

\section{Research procedure}

Ship facilities are observed in every transportation process. Starting from the loading process facility at the port of Tenau, Kupang, a shipping facility, until the facility unloading in the port Tanjung Priok. All facilities used are noted and observed. The pen used is measured every single size to get the value of space allowance. The facilities observed in this study are bedding, loading/ unloading facilities, floor, fence design, sick cattle handling, and space allowance.

\section{Parameters}

- Bedding

Bedding condition and how much used is observed and noted during the transportation.

- Loading/unloading facility

Condition of loading/ unloading facility is observed and noted during the transportation.

- Flooring

Flooring condition in the ship was observed and noted.

- Fence design

The fence design condition in the ship was observed and noted.

- Space allowance

Space allowance was counted by comparing the number of cattle in each pen and the area of the pen. Space allowance cattle during the transport process based on the formula Petherick and Phillips (2009), as follows:

$$
\mathrm{A}=\mathrm{kW}^{0.67}
$$

$A=$ Space allowance $\left(\mathrm{m}^{2}\right)$

$\mathrm{W}=$ body weight $(\mathrm{kg})$

$\mathrm{K}=$ Constants; Depending on the size and shape of livestock, especially cattle length and width ratio.
The minimum standards of allowance space, according to Petherick and Phillips (2009), are:

Livestock only stand during the journey: $\mathrm{A}\left(\mathrm{m}^{2}\right)=0.019 \mathrm{~W}^{0.67}$

Livestock stood up and laid during the journey: $\mathrm{A}\left(\mathrm{m}^{2}\right)=0.027 \mathrm{~W}^{0.67}$

- Sick cattle handling

Handling and facilities used for sick cattle during transportation were observed and noted.

\section{RESULT AND DISCUSSION Bedding}

Bedding is a critical aspect for livestock to feel comfortable during the journey. Bedding used in Camara Nusantara ship is sand with adding a straw. The rice straw bedding is easy and inexpensive to obtain. The bedding used is new, but the bedding used does not cover the entire floor, and only a part of the floor is covered with straw. According to European Commission (2017), bedding straw is given at least $10 \mathrm{~kg}$ $\mathrm{m} 2$, and the bedding should prevent livestock from injured while falling during the transportation process.

Bedding also has to cover the entire floor surface. Bedding cannot absorb all urine impurities or stool for five days of travel, so many cattle slip or drop. Cattle that slip or fall have a higher risk of having dislocation and bruising. Cattle that have bruises can bedding should cover the entire floor surface. Other materials for livestock bedding during the transportation process are sawdust or pellet that has been crushed. Bedding used must be from dry material and have the ability to absorb liquids well. The adequate bedding will also provide a sense of comfort for the cattle to the job (European Commission 2017). According to FAO (2011), bedding should not contain fire hazards, for example, hay. Because the transportation used motor ship, it has the big risk for fire, so that the bedding that contains fire hazard should not be used. 

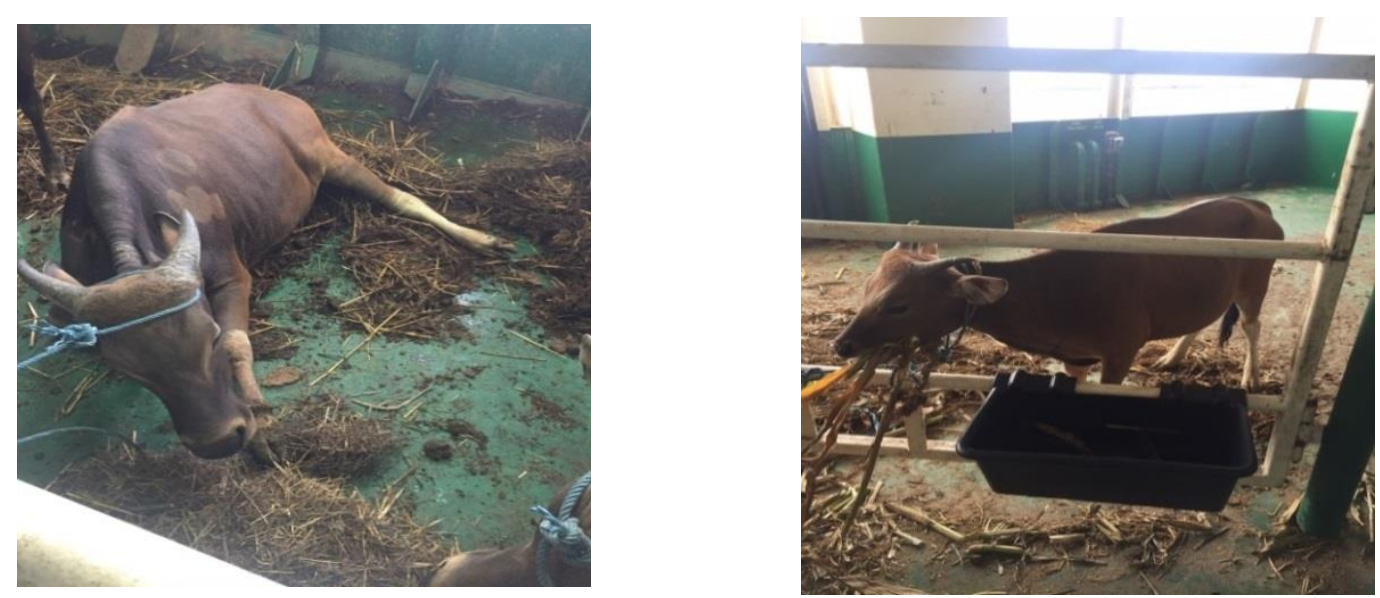

Figure 2. Bedding on Camara Nusantara

\section{Loading and Unloading facilities}

Ramp or loading and unloading paths should be provided during unloading the cattle (ASEL, 2011). The loading cattle in the port of Tenau, Kupang, did not use the ramp, so the ship had to wait for a tidal tide to load cattle. Often cattle should jump when the ship's height or trucks are different. Cattle often refuse to jump, so they are forced by the livestock man to jump by bent the cattle's tail or by forcibly pulling the cattle.
The gap between truck and vessel is covered with hay, reducing the risk for cattle fell when stepping on the grass. The cattle unloading facility in Tanjung Priok Harbor is adequate and uses a ramp. According to Lapworth (1990), the loading and unloading facility should be prepared before the loading/ unloading process. This can minimize the duration of loading and unloading. The length of the duration, the more agitated cattle will be, and cattle will be more stressed.

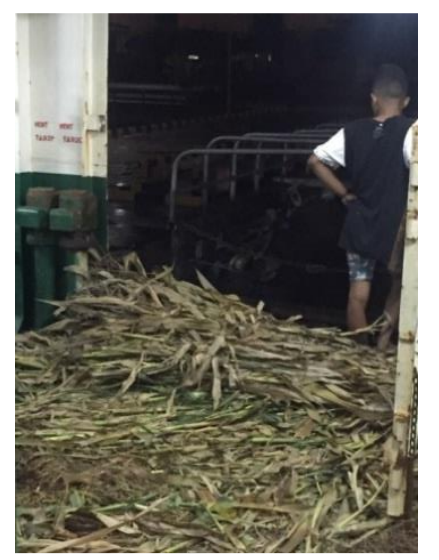

Figure 3. Loading facility in Tenau, Kupang

\section{Ship floor}

According to ASEL (2011), the vessel's floor must be made of a material that does not make cattle fall or slip. The floor cage on the ship Camara Nusantara is taken from iron so that almost all the cattle transported slip during the loading/unloading process.
One solution used is to add straw or Sand on the floor to prevent the cattle slipped or dropped during the loading and unloading process, but still, the cattle dropped or slipped even though already using straw or Sand. It can happen because the straw used is in a wet condition, so that there are still many cattle that fell or slipped. 

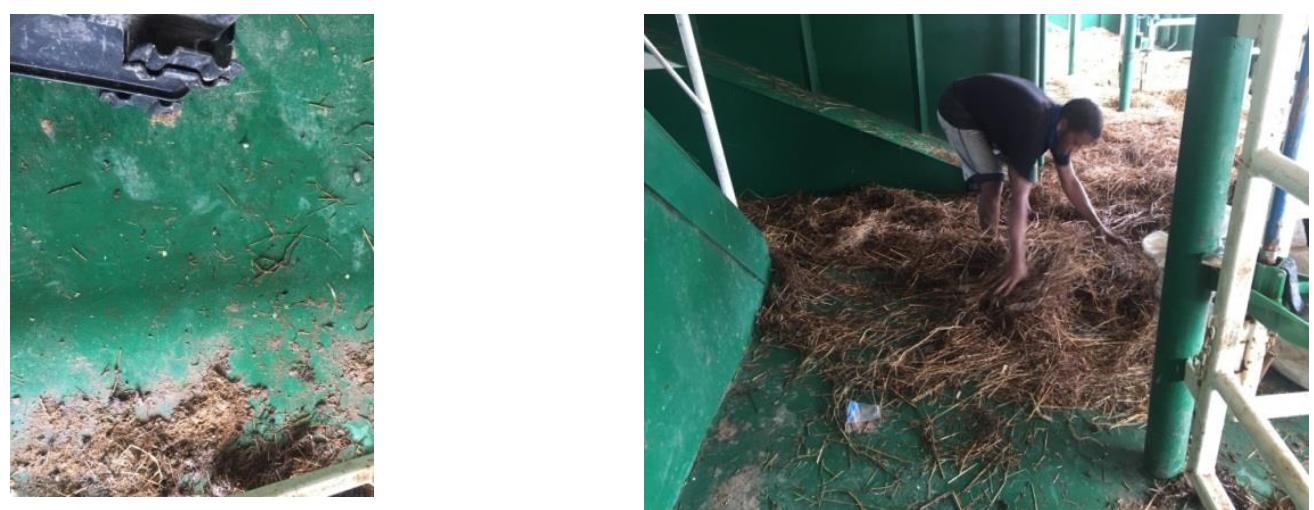

Figure 4. Floor Condition in Camara Nusantara Vessel

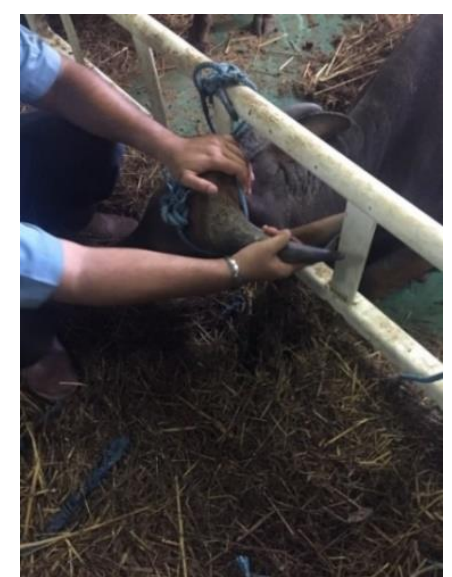

Picture 5. The bull that stuck between the fence

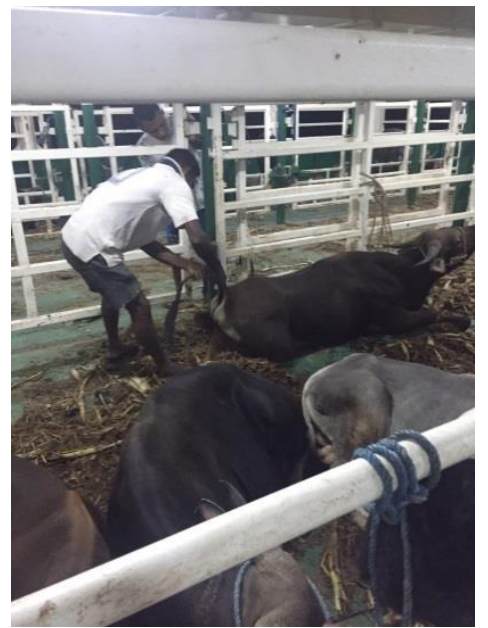

Picture 6. Cattle that diagnosed with dislocation 


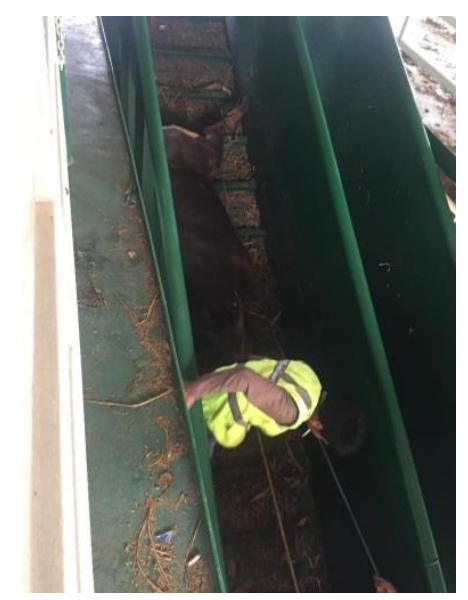

Picture 7. Unloading process of the cattle that have a dislocation

\section{Fence Design}

The design of the fence is not suitable for cattle of a small size. Often the cattle are pinned between the fence, mainly when the cattle that are transported small size or the cattle transported have a large horn. Almost every day, there are cattle trapped in the crack of a fence. A pinned cattle can be at risk for wounds and stress. The fence's design should redesign so that the cattle's head is not stuck between the fence. One solution is to change the fence design of the cage or apply cut beef horns.

\section{Sick cattle}

The handling of sick cattle is different from healthy cattle. According to the European Commission (2017), the sick cattle must be separated from the group and handled immediately. It shows the need for a particular enclosure aimed at accommodating sick cattle separated from the group. However, there is a pen for sick cattle on the Camara Nusantara, but the pen is used to put an unused feed place. One cattle could not rise during the travel process. The veterinarian diagnosed the bull as having a joint dislocation due to the loading process. The bull only can stand on the first day of the trip. Veterinarians gave the sick cattle an injection, but still, could not stand at all. According to the Commonwealth of Australia (2017), cattle that fell must be allowed to stand again without the caretaker's pressure, and the cattle may not experience unacceptable practices such as being withdrawn, lifted by horns, or Drawn on the tail. His practice on the ship Camara Nusantara, a cattle that fell and could not rise, withdrawn his tail and was forced to rise. The cattle in the unloading process are revoked to the truck instead of the Commonwealth of Australia (2017), mentioning that the unrecoverable cattle could not be relocated if the relocation process would cause further pain or stress. According to Animal Health Australia (2016), cattle that can not stand up or move at all should be slaughtered immediately. This immediate slaughter has purposed to reduce the risk of cattle feel pain and stress because of the pain.

\section{Space Allowance}

Enclosure environmental conditions are one of the factors supporting livestock welfare. Environmental conditions that are not suitable will make livestock stressful and will result in livestock weight loss. Excessive or inadequate Space Allowance (SA) During the cattle transportation process will potentially lower the welfare of livestock and profitability. The results of several studies that have been conducted suggest that improper SA can increase the frequency of fallen cattle, injuries, bruises, deaths, and concentrations of cortisol produced (Gonzalez et al., 2015). The area of each enclosure on Camara ships is presented in Figure 8. 

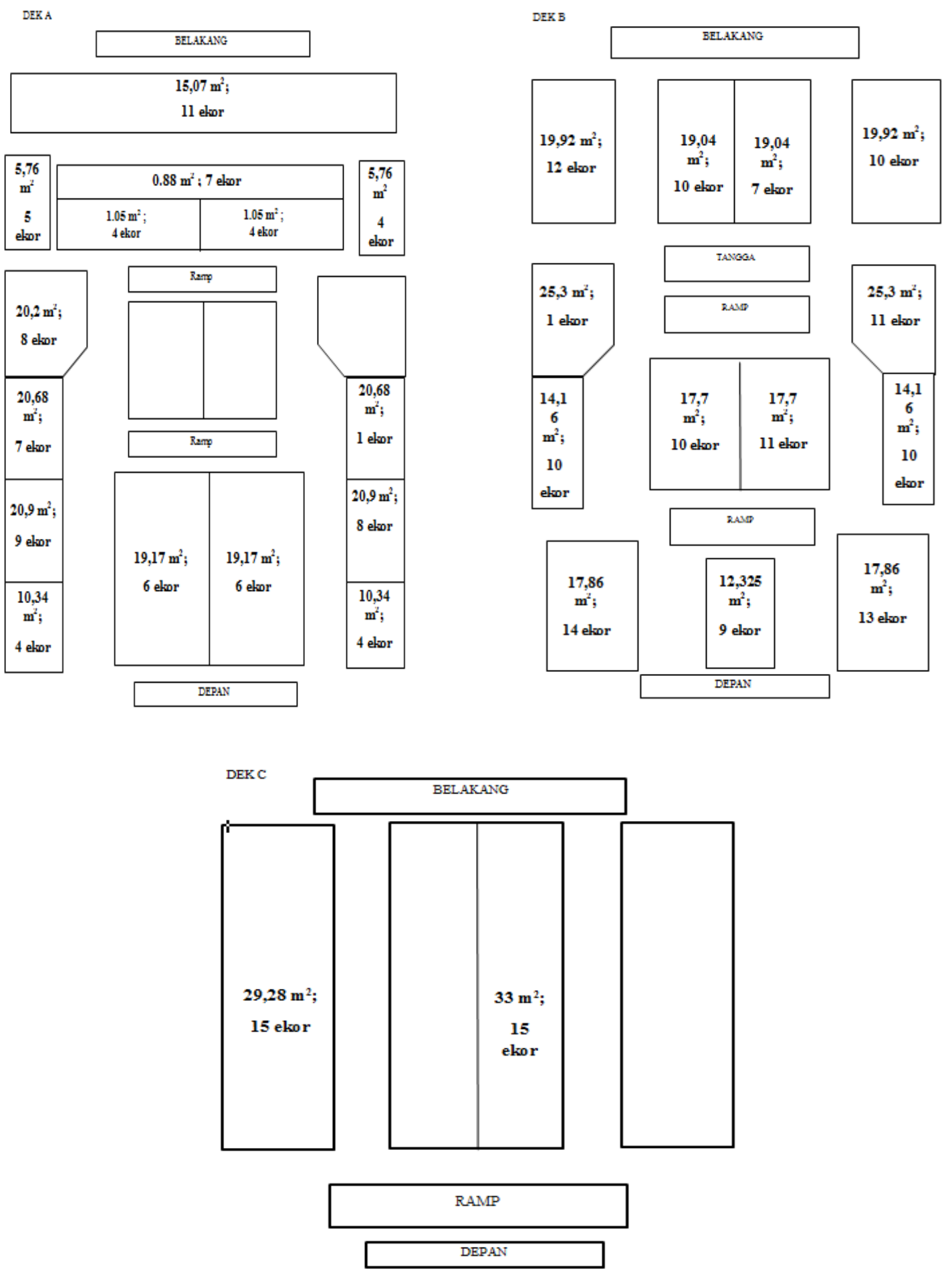

Figure 8. Enclosure Area and Number of Cattle in each of the pen * cattle was tide at one side of the fence

The enclosure area in Camara Nusantara ships ranges from 10-33 m2, which means the density ranges between $1.27-20.68 \mathrm{~m} 2 . /$ head. The cattle were tied on the fence during the transportation process. The area per pen can be seen in Figure 3.
According to the formula Petherick and Phillips (2009), cattle with a weight range of $200 \mathrm{~kg}$ require an area density of 0.93 $\mathrm{m} 2 /$ tail. The pen with more dense can result in falling cattle that can cause injuries or bruises until death in cattle. A less precise 
allocation of cattle causes the size of the cage density. During the transportation process, cattle must be tied to the cage fence so that the cattle are concentrated only on one or two sides of the pen so that the middle or back of the pen is empty hollow.

When calculating the enclosure's density area without taking into account the empty part of the pen, the density of the cage ranges between $0.6-0.8 \mathrm{~m} 2 /$ tail, where this number is below the standard recommended by Petherick and Phillips (2009). However, according to ASEL (2011), cattle weighing $200 \mathrm{~kg}$ needed a space allowance of $0.77 \mathrm{~m}^{2}$, with a record only $5 \%$ of the total cattle that had the horns. According to the European Commission (2017), cattle weighing \pm 200 $\mathrm{kg}$ requires a space allowance of $0.70 \mathrm{~m}^{2}$. The horned cattle must have a more extensive allowance space, which is by the addition of $10 \%$ space. Tarrant (1990) says the mode of transportation with a high density can cause bruising or injury to the livestock and decrease the quality of the meat. According to Whitting (2000), cattle placed with lower-density areas have lower heart rates than cattle placed on cages with a high-density area. Whitting (2000) also explains that dense areas of density can also be detrimental. An area of density that is too dense can increase the bruising score because livestock is at risk for falling more. Space allowance can affect cattle's behavior during the trip, especially the position of livestock that is liked during transportation and the breeding of cattle to lie down and spread the cattle to become tired (Jury 2013). On the other hand, space allowance that is too wide can also cause livestock to fall. (European Commission 2017).

\section{CONCLUSIONS}

There is still much lack of the facility used in Camara Nusantara. The inappropriate facility can make cattle transported become stress and resulting in weight loss. All the facilities used can be reevaluated so that all the Camara Nusantara facilities can be adjusted with Indonesia's livestock breed.

\section{ACKNOWLEDGMENT}

This research was supported by NICHE (Netherland Initiative For Capacity De-velopment In Higher Education), PT. Pelni Indonesia, and all the ship's crew of Camara Nusantara 3.

\section{REFERENCES}

Animal Health Australia. (2016). Australian Animal Welfare Standards and Guidelines for cattle (1st ed.).

ASEL. (2011). Australian Position Statement on the Export of Livestock. Department of Agriculture, Fisheries, and Forestry.

European Commission. (2017). Guide to Good Practices for Transport Cattle. EU Comission.

Food Agriculture Organization. (2011). Rural Structure in the Tropics: Design and development. Food and agriculture organization of the united nations.

González, L. A., Schwartzkopf-Genswein, K. S., Bryan, M., Silasi, R., \& Brown, F. (2012). Space allowance during commercial long distance transport of cattle in North America1. Journal of Animal Science, 90(10), 3618-3629. https://doi.org/10.2527/jas.2011-4771

Haryana, A., \& Nuryati, Y. (2016). The role of livestock vessel in expediting the distribution flow and reducing the logistic cost of beef from producer's center to consumer's center. JURNAL Pusdiklat Perdagangan, 2(1), 78-85.

Jury, L. L. R. (2013). Effect of Trailer Stocking Density on Cattle Behavior During Truck Transport. Mississippi State Univ.

Lapworth, J. W. (1990). Standards for loading and unloading facilities for cattle. Applied Animal Behaviour Science, 28(1-2), 203-211. https://doi .org/10.1016/0168-1591(90)90054-H

Petherick, J. C., \& Phillips, C. J. C. (2009). Space allowances for confined livestock and their determination from allometric principles. Applied Animal Behaviour Science, 117(1-2), 1-12. 
https://doi.org/10.1016/j.applanim.200 8.09.008

Tarrant, P. V. (1990). Transportation of cattle by road. Applied Animal Behaviour Science, 28(1-2), 153-170. https://doi.org/10.1016/0168-1591(90)
90051-E

Whiting, T. L. (2000). Comparison of minimum space allowance standards for transportation of cattle by road from 8 authorities. Canadian Veterinary Journal, 41(11), 855-860. 